Original Article

\title{
EVALUATION OF ANTI-OBESITY EFFECT OF AQUEOUS EXTRACT OF MUCUNA PRURIENS SEEDS ON RATS
}

\author{
JAVID MANSURI ${ }^{a}$, ARCHANA PARANJAPE \\ aParul Institute of Pharmacy, Parul University, Waghodia, Gujarat, India, bEdutech Learning Solutions Pvt. Ltd., Vadodara, India \\ Email: javid.mansuri@gmail.com
}

Received: 20 Oct 2016 Revised and Accepted: 17 Jan 2017

\begin{abstract}
Objective: Evaluation of the anti-obesity effect of aqueous extract of Mucuna pruriens seeds on rats.

Methods: Male Sprague-Dawley (SD) rats were subjected to high-fat diet (HFD) for 12 wk. L-DOPA (12.5 mg/kg, p. o.) as standard drug and aqueous extract of Mucuna pruriens (AEMP) seeds (200 mg/kg, p. o. and $400 \mathrm{mg} / \mathrm{kg}$, p. o.) as test drugs were administered in last 4 wk along with HFD. Body weight, food intake, body mass index (BMI), serum total cholesterol (TC), triglyceride (TG) and high-density lipoprotein (HDL) levels were measured at the end of fourth, eighth and twelfth wk, while white adipose tissue (WAT) mass and brain dopamine levels were measured at the end of the twelfth wk.

Results: AEMP (200 mg/kg, p. o.) and $(400 \mathrm{mg} / \mathrm{kg}$, p. o.) treated groups showed a significant decrease in food intake and weight gain without altering BMI. Moreover, TG levels were lower in treated groups as compared to the HFD group, but no significant changes were observed in TC and HDL levels. L-DOPA-treated group showed a significant decrease in body weight, food intake, BMI and WAT. Both AEMP and L-DOPA-treated groups showed an increase in brain dopamine levels as compared to disease control group $(p<0.05)$.
\end{abstract}

Conclusion: L-DOPA and AEMP showed anti-obesity activity by reducing body weight gains, food intake and WAT weights; modulating TG with increased brain dopamine level which correlates to the inhibitory action of dopamine on reward mechanism.

Keywords: Mucuna pruriens, Dopamine, High fat diet, Body weight, Food intake

(C) 2016 The Authors. Published by Innovare Academic Sciences Pvt Ltd. This is an open access article under the CC BY license (http://creativecommons.org/licenses/by/4.0/] DOI: http://dx.doi.org/10.22159/ijpps.2017v9i3.15781

\section{INTRODUCTION}

Obesity is a medical condition in which life is hindered by excess body fat. The generally accepted benchmark is the BMI. The world health organisation (WHO) classifies population with a BMI of $<18.5$ $\mathrm{kg} / \mathrm{m}^{2}$ as underweight, and those with a BMI of $18.5-24.9 \mathrm{~kg} / \mathrm{m}^{2}$ as normal weight. A BMI in the range of $25.0-29.9 \mathrm{~kg} / \mathrm{m}^{2}$ as grade 1 overweight. If it is between $30.0-39.9 \mathrm{~kg} / \mathrm{m}^{2}$, the patient is said to be obese or grade 2 overweight, while those with a BMI of $40 \mathrm{~kg} / \mathrm{m}^{2}$ are deemed to be grade 3 overweight or morbidly obese. The prevalence of obesity is increasing not only in adults but also among children and adolescents. The prevalence of obesity has increased steadily over the past five decades and may have a significant impact on the quality adjusted life years [1]. The causes of obesity may include dietary, exercise, social, cultural and financial factors. Sibutramine was widely marketed and prescribed until 2010 when it was withdrawn after a large study showed that it increased the risk of cardiovascular events and strokes and had minimal efficacy. An endocannabinoid receptor antagonist, rimonabant was withdrawn from the market due to concerns about its safety, including the risk of seizures and suicidal tendencies. At present only one drug orlistat has been approved for long-term use in the treatment of obesity. Orlistat promotes 5 to $10 \%$ loss of body weight and has their own limitations and side effects. This currently licensed drug is best when used in combination with diet, exercise, and behaviour change regimens. However, they do not cure obesity and weight rebound when discontinued. Some drugs are employed to treat clinical obesity is associated with adverse effects such as nausea, insomnia, constipation, gastrointestinal problems, and potential adverse cardiovascular effects. Thus, there is a great demand for the search of new and safer anti-obesity medicines [2].

Several neurotransmitters (dopamine, norepinephrine and serotonin), as well as peptides and hormones like ghrelin, are involved in the regulation of food intake [3, 4]. Of particular interest is dopamine, since this neurotransmitter seems to regulate food intake [5] by modulating food reward via the meso-limbic circuitry of the brain [6]. In fact, drugs that block dopamine $\mathrm{D}_{2}$ receptors increase appetite and result in significant weight gain $[7,8]$ whereas drugs that increase brain dopamine are anorexigenic [9-11]. Additionally, an increase in body weight is a side effect of many commonly used drugs. Particularly, anti-dopaminergically acting neuroleptics, tricyclic antidepressants, lithium, and some anticonvulsants contribute to weight gain. Similarly, in the obesity body mass index is negatively correlated with $\mathrm{D}_{2}$ receptor density in the striatum [12, 13], which might reflect neuroadaptation secondary to over stimulation with palatable food $[14,15]$. Thus, increased food intake may be a compensatory behaviour for low dopaminergic drive [16, 17]. Recently it is reported that lower striatal activation in response to food intake was associated with obesity. Furthermore, this relation was modulated by genetically determined $D_{2}$ receptor availability $[18,19]$.

Plants have been the basis for traditional medicine systems. Numerous preclinical and clinical studies, with various herbal medicines, have reported significant improvement in controlling body weight, without any noticeable adverse effects.

Mucuna pruriens Linn. DC. (Leguminosae) known as "velvet bean" and "atmagupta" is a climbing legume, endemic in India and in other parts of the tropics including Central and South America. In the Ayurvedic system of medicine, Mucuna pruriens was used for the management of male infertility [20], nervous disorders [21] and also as an aphrodisiac [22]. Mucuna pruriens seed powder contains a large amount of L-DOPA (1.5\%), which is a dopamine precursor and effective remedy for the relief in Parkinson's disease [23]. Mucuna pruriens seeds in addition to L-DOPA contain 5-hydroxytryptamine (5-HT), tryptamine, mucunine and mucunadine. Ethanolic extract of Mucuna pruriens shows protection against haloperidol-induced tardive dyskinesia in rats [24]. Mucuna pruriens has been reported to inhibit chlorpromazine-induced hyperprolactinaemia in man [25]. Mucuna pruriens has proven to be more effective than L-DOPA in parkinson's disease in an animal model [26]. It also shows antidiabetic [27], anticancer [28], anti-oxidant [29], anti-hyperlipidemic 
[30] and protective effect against nephrotoxicity [31]. These reports led us to hypothesise that high content of dopamine in Mucuna pruriens seed could serve as a potent therapeutic agent for the obesity. However, their efficacy needs to be scientifically evaluated in vivo experiments. In light of above observations, current investigation was carried out to study the effect of dopaminecontaining plant Mucuna pruriens (L.) DC. var. utilis in HFD induced obesity on rats.

\section{MATERIALS AND METHODS}

\section{Chemicals and reagents}

L-DOPA was obtained from Torrent Research Centre, Bhat, India; all other reagents used in this study were of analytical grade.

\section{Preparation of extracts}

Seeds of Mucuna pruriens (L.) DC. var. utilis were purchased from the authorised dealer and authenticated by National Institute of Science Communication and Information Resources (voucher specimen no.: NISCAIR/RHMD/consult/2016/3001-28-1), India. For the extraction, freshly collected seeds of Mucuna pruriens were dried in the shade and pulverized to get a coarse powder. One kg seed powder of Mucuna pruriens was initially defatted with $750 \mathrm{ml}$ of petroleum ether and then aqueous extract was prepared by cold maceration method. After $24 \mathrm{~h}$, the extract was filtered using whatman filter paper (No. 1) and then concentrated under reduced pressure (bath temp. $50{ }^{\circ} \mathrm{C}$ ) and finally dried in a vacuum desiccator [31].

\section{Experimental animals}

Male SD rats weighing 250-300 g were used in the study. The animals were housed in a group of 6 rats per cage under wellcontrolled conditions of temperature $\left(22 \pm 2{ }^{\circ} \mathrm{C}\right)$, humidity $(55 \pm 5 \%)$ and light-dark cycles $(12: 12 \mathrm{~h})$. They were maintained under standard environmental conditions and were fed a standard rat chow diet with water given ad libitum. The study was approved by Institutional Animal Ethical Committee, Parul institute of pharmacy, Parul University, Vadodara, Gujarat, India (PIPH 19/12).

\section{Experimental design}

Male SD rats were acclimatised for 1 wk. Obesity in the rat was induced by a HFD. The composition of HFD is mentioned in table 1 $[32,33]$. The rats were divided into five groups consisting of six rats in each as follows:

Group I: Normal protein diet (NPD)

Group II: HFD

Group III: HFD+AEMP (200 mg/kg, p. o.)

Group IV: HFD+AEMP (400 mg/kg, p. o.)

Group V: HFD+L-DOPA (12.5 mg/kg, p. o.)

Group, I was fed NPD, while groups II, III, IV and V were fed HFD for 12 $\mathrm{wk}$ that is throughout the study. At the end of $8 \mathrm{wk}$, group III, IV and V were treated with test extract or standard drug for $4 \mathrm{wk}$ along with HFD. Body weight, food intake, BMI and serum TC, TG and HDL levels were measured at the end of 4, 8 and $12 \mathrm{wk}$. The epididymal WAT mass and brain dopamine level were measured at the end of $12 \mathrm{wk}$.

Table 1: Composition of HFD

\begin{tabular}{lll}
\hline Ingredients & Weight (g) & Energy (Kcal) \\
\hline Powdered NPD & 50 & 0.21 \\
Animal fat & 20 & 0.18 \\
Sucrose & 29.8 & 0.11 \\
Sodium chloride & 0.2 & - \\
& $100 \mathrm{~g}$ & $0.5 \mathrm{Kcal} / 100 \mathrm{~g}$ \\
\hline
\end{tabular}

\section{Collection of blood samples}

At the end of fourth, eighth and twelfth wk, blood was collected under inhalation anaesthesia by a retro-orbital puncture from overnight fasted animals. Blood was allowed to clot for $30 \mathrm{~min}$ at room temperature. Serum was separated by centrifugation at $4000-$ $5000 \mathrm{rpm}$ for $15 \mathrm{~min}$ and analysed for serum TC, TG and HDL levels.

\section{Estimation of TC, TG and HDL levels}

TC, TG and HDL were estimated by using a Bayer diagnostic kit (Bayer Diagnostic India Ltd.)

\section{Fat pad analysis}

At the end of the $12 \mathrm{wk}$, animals were decapitated between 09:00 and 12:00 h. After sacrificing by decapitation, the epididymal WAT was dissected out. The collected fat was weighed immediately and compared with the other groups [34].

\section{Brain dopamine levels \\ Preparation of tissue extract}

On the last day of the experiment, rats were sacrificed, and the whole brain was dissected out, weighed and was homogenised in 3 $\mathrm{ml} \mathrm{HCl}$ butanol in a cool environment. The sample was subsequently centrifuged for $10 \mathrm{~min}$ at $2000 \mathrm{rpm} .0 .8 \mathrm{ml}$ of the supernatant phase was removed and added to an eppendorf reagent tube containing 2 $\mathrm{ml}$ of heptane and $0.25 \mathrm{ml} 0.1 \mathrm{M} \mathrm{HCl}$. After $10 \mathrm{~min}$, the tube was shaken and centrifuged under the same conditions to separate two phases. Upper organic phase was discarded and the aqueous phase was used for dopamine assay.

\section{Dopamine assay}

$0.02 \mathrm{ml}$ of the HCL phase $+0.005 \mathrm{ml} 0.4 \mathrm{M} \mathrm{HCL}+0.01 \mathrm{ml}$ EDTA

\section{$\downarrow$}

$0.01 \mathrm{ml}$ iodine solution was added for oxidation

After $2 \mathrm{~min}, 1 \mathrm{ml}$ sodium thiosulphate in $5 \mathrm{M}$ sodium hydroxide was added to stop the reaction

$10 \mathrm{M}$ acetic acid was added 1.5 min later

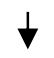

Solution was then heated to $100{ }^{\circ} \mathrm{C}$ for $6 \mathrm{~min}$

Excitation and emission spectra were read (330 to $375 \mathrm{~nm}$ ) in a
spectrofluorophotometer

(Shimadzu RF-5301 PC) when the samples again reached room temperature

Tissue values (fluorescence of tissue extract minus fluorescence of tissue blank) were compared with an internal reagent standard (fluorescence of internal reagent standard minus fluorescence of internal reagent blank). Tissue blanks for the assay were prepared by adding the reagents of the oxidation step in reversed order (sodium thiosulphate before iodine). Internal reagent standards were obtained by adding $0.005 \mathrm{ml}$ bidistilled water and $0.1 \mathrm{ml} \mathrm{HCl}$ butanol to $20 \mathrm{ng}$ of dopamine standard [35, 36].

\section{Statistical analysis}

All data were presented as mean \pm standard error of means (SEM). Oneway analysis of variance (ANOVA) followed by Tukey's test was used for statistical analysis to compare more than two groups, while two-way ANOVA was used to compare values of the different time period of the same group. $P$ values of less than 0.05 were considered significant.

\section{RESULTS}

\section{Body weight}

Body weight was measured every wk till twelve wk. The body weights of all groups (II, III, IV and V) were significantly increased 
compared to the control group (group I) for first $8 \mathrm{wk}$. After $12 \mathrm{wk}$ the L-DOPA and AEMP (400 mg/kg) groups had significantly $(p<0.05)$ lower mean body weights than HFD group. The mean body weight in the HFD group increased by $46.67 \mathrm{~g}$ after $12 \mathrm{wk}$ of the experimental period, whereas L-DOPA and AEMP (400 mg/kg) group lost $23 \mathrm{~g}$ and $30 \mathrm{~g}$ respectively. In normal and AEMP (200 $\mathrm{mg} / \mathrm{kg}$ ) treated groups mean body weight gain was found to be 9.66 $\mathrm{g}$ and $6.66 \mathrm{~g}$ respectively (table 2 ).

Table 2: Body weights at different time interval

\begin{tabular}{|c|c|c|c|c|c|c|}
\hline & & Normal & HFD & L-DOPA & AEMP (200 mg/kg) & AEMP (400 mg/kg) \\
\hline \multirow{3}{*}{$\begin{array}{l}\text { Body weight } \\
\text { (g) }\end{array}$} & Initial & $321.67 \pm 11.67$ & $268.34 \pm 14.24$ & $270.00 \pm 15.00$ & $303.34 \pm 3.33$ & $303.34 \pm 8.81$ \\
\hline & $8^{\text {th }} \mathrm{wk}$ & $369.66 \pm 15.275(55)$ & $\begin{array}{l}420.00 \pm 35.11 \\
(152.3)^{*}\end{array}$ & $\begin{array}{l}390.00 \pm 30.00 \\
(120.67)^{\wedge}\end{array}$ & $\begin{array}{l}460.00 \pm 25.16 \\
(147.3)^{\wedge}\end{array}$ & $443.33 \pm 12.01(140.0)^{\star}$ \\
\hline & $12^{\text {th }} \mathrm{wk}$ & $\begin{array}{l}379.33 \pm 14.53 \\
(9.66)\end{array}$ & $\begin{array}{l}466.67 \pm 38.44 \\
(46.67)^{\times}\end{array}$ & $\begin{array}{l}366.66 \pm 33.33(- \\
23.33)^{+}\end{array}$ & $466.67 \pm 33.33(6.66)^{+}$ & $413.33 \pm 6.67(-30.00)^{+}$ \\
\hline
\end{tabular}

Values are expressed as means \pm SEM, n=6 in each group. Values are significantly different $(p<0.05)$ by one way ANOVA followed by Tukey's test, ${ }^{*}, \mathbf{\Delta}$ of body weight gained during the first $8 \mathrm{wk}$ of the experimental period, ${ }^{\mathrm{x},+} \mathrm{g}$ of body weight gained altered after $12 \mathrm{wk}$ experimental period.

\section{Food intake}

There was a significant increase in food intake per wk among the HFD treated rats as compared to the normal diet-fed rats up to $8 \mathrm{wk}$.
The rats treated with AEMP (200 mg/kg, p. o. and $400 \mathrm{mg} / \mathrm{kg}$, p. o.) showed a significant decrease in food intake as compared to the HFD group. L-DOPA-treated group also exhibited a significant reduction in food intake as compared to the HFD group (fig. 1).

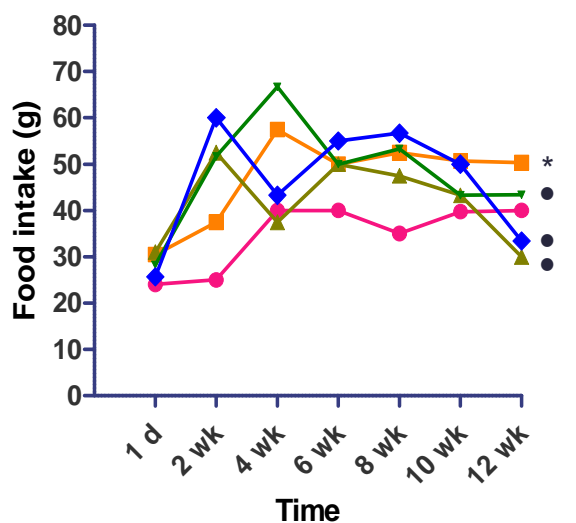




\section{Serum lipid profile}

Feeding of HFD caused a significant $(p<0.05)$ increase in serum levels of TG as compared to normal diet fed rats. L-DOPA and AEMP (200 $\mathrm{mg} / \mathrm{kg}$ and $400 \mathrm{mg} / \mathrm{kg}$ ) treated groups showed significantly lower serum TG levels than in HFD group. However, no alteration was found in TC and HDL levels by treatment with either drug (table 3 ).

\section{Brain dopamine levels}

Brain dopamine levels of HFD group were significantly $(p<0.05)$ reduced compared with the control group. However, groups administered with L-DOPA and AEMP $(200 \mathrm{mg} / \mathrm{kg}$ and $400 \mathrm{mg} / \mathrm{kg})$ showed significant $(p<0.05)$ increase in brain dopamine levels as compared to the HFD group (fig. 3).

Table 3: Serum levels of TG, TC and HDL of rat (after the $12 \mathrm{wk}$ experimental period)

\begin{tabular}{lllll}
\hline Serum level (mg/d) & Groups & & & \\
\cline { 2 - 5 } & Normal & HFD & L-DOPA & AEMP (200 mg/kg) \\
\hline TG & $75.33 \pm 7.86$ & $155.0 \pm 5.29^{*}$ & $118.3 \pm 4.41^{\bullet}$ & $95.33 \pm 4.84^{\bullet}$ \\
TC & $58.67 \pm 10.37$ & $70.67 \pm 6.489$ & $85.67 \pm 3.33$ & $63.00 \pm 9.07$ \\
HDL & $37.93 \pm 1.67$ & $40.33 \pm 4.48$ & $48.70 \pm 3.2$ & $37.47 \pm 5.23$ \\
\hline
\end{tabular}

Results are presented as means \pm SEM, $n=6$., ${ }^{\bullet}$, Means with different letters in the same row are significantly different $(p<0.05)$ by one-way ANOVA followed by Tukey's test.

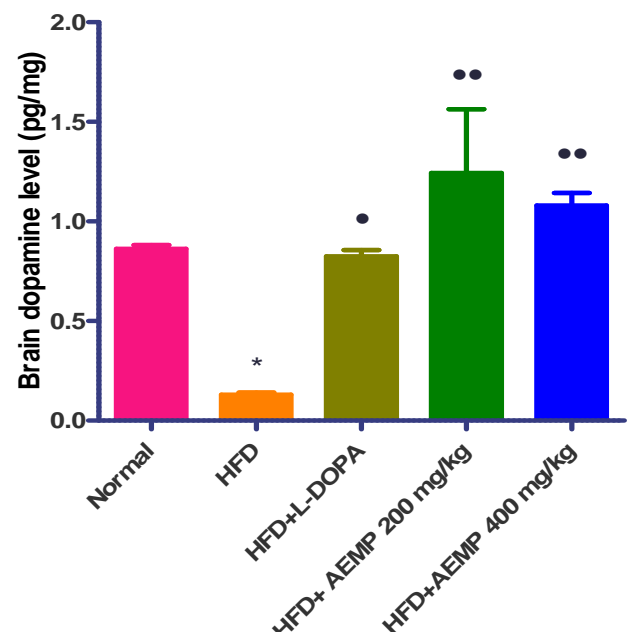

Fig. 3: Effect of L-DOPA and AEMP on brain dopamine level, Each bar represents the mean \pm SEM, $n=6 ;{ }^{*}, p<0.05$ compared to group I, $\bullet, p<0.01$ compared to Group II (analysed by one-way ANOVA followed by Tukey's test)

\section{White adipose tissue}

Feeding a high-fat diet for 12 wk produced a significant $(p<0.05)$ increase in epididymal WAT weight of HFD treated the group as compared to normal diet fed rats.

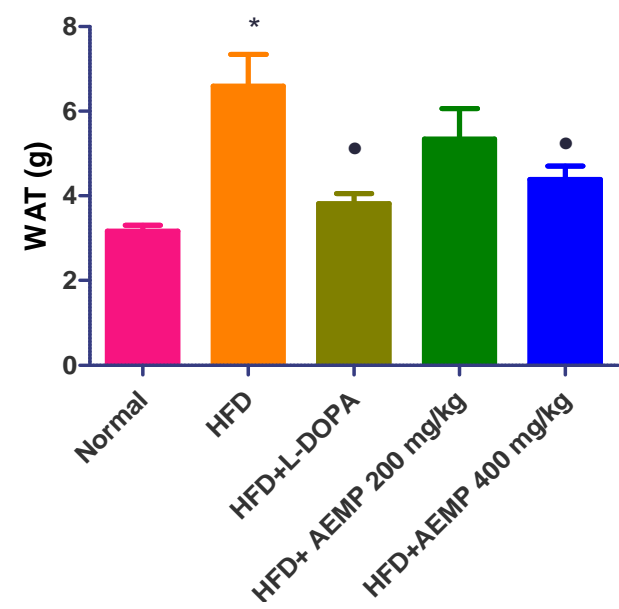

Fig. 4: Effect of L-DOPA and AEMP on white adipose tissue, Each bar represents the mean $\pm S E M, n=6 ;{ }^{*}, p<0.05$ compared to group I, $\bullet, p<0.05$ compared to Group II (analysed by one-way ANOVA followed by Tukey's test)
There were a significant reduction in the epididymal fat mass in the L-DOPA and AEMP $(400 \mathrm{mg} / \mathrm{kg}$ ) treated groups while no significant alteration was observed in AEMP $(200 \mathrm{mg} / \mathrm{kg})$ group as compared to HFD (fig. 4).

\section{DISCUSSION}

In the present study, the anti-obesity activity of dopamine and dopamine-containing plant Mucuna pruriens was investigated on HFD induced rat model for obesity.

During the first $8 \mathrm{wk}$ of the experimental period, administration of HFD was found to increase the body weight in all groups. Treatment with L-DOPA and AEMP $(200 \mathrm{mg} / \mathrm{kg}$ and $400 \mathrm{mg} / \mathrm{kg}$ ) for subsequent $4 \mathrm{wk}$ attenuated the increase in body weight as compared to nontreatment HFD group. Further, in L-DOPA group and in AEMP (400 $\mathrm{mg} / \mathrm{kg}$ ) group there was a significant reduction in body weight as compared to pre-treatment weights in rats in these groups. The reduction in body weight in treated groups was found to be convergent with a reduction in food intake observed in all treated groups as compared to the HFD group. In L-DOPA group, this was supported further by significant reduction of BMI. Lowering of BMI by AEMP $(200 \mathrm{mg} / \mathrm{kg}$ and $400 \mathrm{mg} / \mathrm{kg}$ ) although not statistically significant also supports the anti-obesity activity of Mucuna pruriens.

The results of present study correlate with the previous studies showing the role of brain dopamine and its receptors in reward mechanism and weight gain. In the present study, brain dopamine levels were found to be increased in all treatment groups as compared to HFD groups which confirm the body weight reducing the effect of dopamine.

White adipose tissue mass was significantly reduced by L-DOPA and AEMP $(400 \mathrm{mg} / \mathrm{kg})$ but not significantly altered in AEMP $(200$ $\mathrm{mg} / \mathrm{kg}$ ) treated groups. Although AEMP $(200 \mathrm{mg} / \mathrm{kg})$ treated group showed prevention of accumulation of adipose tissue and so adiposity. Serum TG levels were significantly decreased in all treated groups with no effect on TC and HDL levels. This shows that the antiobesity effect seen with L-DOPA and Mucuna pruriens in the present study is not because of their effect on lipid levels and it is mainly governed centrally by altering brain dopamine levels.

\section{CONCLUSION}

The present study revealed that Mucuna pruriens seeds had weight lowering agent. The brain dopamine assay indicated that the presence of L-DOPA (dopamine precursor) in the seed extracts might be the constituents responsible for these activities.

\section{CONFLICT OF INTERESTS}

The authors declare that there is no conflict of interest

\section{REFERENCES}

1. World Health Organization: Obesity and overweight. Available from: http://www.who.int/dietphysicalactivity/publications/ facts/obesity/. [Last accessed on 15 Sep 2016] 
2. Yanovski SZ, Yanovski JA. Long-term drug treatment for obesity: a systematic and clinical review. JAMA 2014;311:74-86.

3. Gandhi M, Swaminathan S. Ghrelin and obesity an update. Int J Pharm Clin Res 2014;6:284-7.

4. Schwartz MW, Woods SC, Porte JR, Seeley RJ, Baskin DG. Central nervous system control of food intake. Nature 2000;404:661-71.

5. Martel P, Fantino M. Mesolimbic dopaminergic system activity as a function of food reward: a microdialysis study. Pharmacol Biochem Behav 1996;53:221-6.

6. Balcioglu A, Wurtman RJ. Effects of phentermine on striatal dopamine and serotonin release in conscious rats: in vivo microdialysis study. Int J Obesity Related Metab Disorders 1998;22:325-8.

7. Baptista T. Body weight gain induced by antipsychotic drugs: mechanisms and management. Acta Psychiatr Scand 1999; 100:3-16.

8. Wetterling T. Bodyweight gain with atypical antipsychotics. A comparative review. Drug Saf 2001;24:59-73.

9. Towell A, Muscat R, Willner P. Behavioural microanalysis of the role of dopamine in amphetamine anorexia. Pharmacol Biochem Behav 1988;30:641-8.

10. Foltin RW, Fischman MW, Nautiyal C. The effects of cocaine on food intake of baboons before, during, and after a period of repeated desipramine. Pharmacol Biochem Behav 1990; 36:869-74.

11. Wang GJ, Wolkow ND, Wong CT. Behaviour and cardiovascular effects of intravenous methylphenidate in normal subjects and cocaine abusers. European Addiction Res 1997;3:49-54.

12. Wang GJ, Volkow ND, Logan J, Pappas NR, Wong CT, Zhu W, et al. Brain dopamine and obesity. Lancet 2001;357:354-7.

13. Haltia LT, Rinne JO, Merisaari H, Maguire RP, Savontaus E, Helin S, et al. Effects of intravenous glucose on dopaminergic function in the human brain in vivo. Synapse 2007;61:748-56.

14. Colantuoni C, Schwenker J, McCarthy J, Rada P, Ladenheim B, Cadet JL, et al. Excessive sugar intake alters binding to dopamine and mu-opioid receptors in the brain. Neuroreport 2001;12:3549-52.

15. Bello NT, Lucas LR, Hajnal A. Repeated sucrose access influences dopamine $D_{2}$ receptor density in the striatum. Neuroreport 2002;13:1575-8.

16. Paul M, Paul J. Dopamine $\mathrm{D}_{2}$ receptors in addiction-like reward dysfunction and compulsive eating in obese rats. Nat Neurosci 2010;13:635-41.

17. Davis C, Strachan S, Berkson M. Sensitivity to reward: implications for overeating and overweight. Appetite 2004;42:131-8.

18. Stice E, Spoor S, Bohon C, Small DM. The relation between obesity and blunted striatal response to food is moderated by TaqIA A1 allele. Science 2008;322:449-52.

19. Inoue K, Kiriike N, Fujisaki Y, Okuno M, Ito H, Yamagami S, et al. $\mathrm{D}_{2}$ receptors in the ventrolateral striatum are involved in feeding behaviour in rats. Pharmacol Biochem Behav 1995;50:153-61.

20. Jayanthi A. Effect of Mucuna pruriens seeds on fertility of male albino rats Rattus norvegicus. J Pharm Res 2011;4:233-6.

21. Manyam BV, Dhanasekaran M, Hare T. Neuroprotective effects of antiparkinson drug Mucuna pruriens. Phytother Res 2004;18:706-12.
22. Kirtikar KR, Basu BD. Indian medicinal plants. Dehradhun: International book distributors, booksellers and publishers; 1996.

23. Kasture S, Pontis S, Pinna A, Schintu N, Spina L, Longoni R, et al. Assessment of symptomatic and neuroprotective efficacy of Mucuna pruriens seed extract in a rodent model of Parkinson's disease. Neurotox Res 2009;15:111-22.

24. Dhanasekaran S, Ratheeshkumar K, Palayan M. Effect of ethanolic seed extract of Mucuna pruriens on haloperidolinduced tardive dyskinesia in rats. Int J Pharm Sci Rev Res 2010;3:106-13.

25. Dhanasekaran S, Vaidya RA, Sheth AR, Aloorkar SD, Rege NR, Bagadia VN, et al. The inhibitory effect of the cowhage plantMucuna pruriens and L-DOPA on chlorpromazine-induced hyperprolactinaemia in man. Neurology 1978;26:177-8.

26. Hussain G, Gazala H. Mucuna pruriens proves more effective than L-DOPA in Parkinson's disease animal model. Phytother Res 1997;2:419-23.

27. Majekodunmi SO, Oyagbemi AA, Umukoro S, Odeku OA. Evaluation of the antidiabetic properties of Mucuna pruriens seed extract. Asian Pac J Trop Med 2011;4:632-6.

28. Rajeshwar Y, Gupta M, Mazumder UK. Antitumor activity and in vivo antioxidant status of Mucuna pruriens (Fabaceae) seeds against ehrlich ascites carcinoma in Swiss albino mice. Iranian J Pharmacol Ther 2005;4:46-53.

29. Sonpetkar JM, Nipate SS, Shenoy PA, Chaudhari PD. In vitro antioxidant activity of ethanolic extract of Mucuna pruriens (L.) DC. seeds. J Pharm Res 2012;5:2769-72.

30. Eze ED, Mohammed A, Musa KY, Tanko Y, Isa AS. Effect of ethanolic leaf extract of Mucuna pruriens (fabaceae) on lipid profile in alloxan-induced diabetic Wistar rats. Br J Pharmacol Toxicol 2012;3:102-9.

31. Modi KP, Patel MN, Goyal RK. Protective effects of aqueous extract of Mucuna pruriens Linn. (DC) seed against gentamicininduced nephrotoxicity and oxidative stress in rats. Iran J Pharmacol Ther 2008;7:131-5.

32. Barnard RJ, Faria DJ, Menges JE, Martin DA. Effects of a high-fat, sucrose diet on serum insulin and related atherosclerotic risk factors in rats. Atherosclerosis 1993;2:229-36.

33. Gupta S, Manish K. Histomorphological and hypolipidemic effects from the whole plant of Gymnema sylvestre in high cafeteria dietinduced obese rat model. J Pharm Biomed Sci 2010;2:1-9.

34. Loncar D, Afzelius BA, Cannon B. Epididymal white adipose tissue after cold stress in rats. I. nonmitochondrial changes. J Ultrastruct Mol Struct Res 1988;101:109-22.

35. Schlumfjf M, lichtensteiger W, langemann H, Waser PG, Hefti F. A fluorometric micro method for the simultaneous determination of serotonin, noradrenaline and dopamine in milligram amounts of brain tissue. Biochem Pharmacol 1974;23:2337-446.

36. Jacobowitz D, Richardson J. Method for the rapid determination of norepinephrine, dopamine and serotonin in the same brain region. Pharmacol Biochem Behav 1977;8:515-9.

\section{How to cite this article}

- Javid Mansuri, Archana Paranjape. Evaluation of the antiobesity effect of aqueous extract of Mucuna pruriens seeds on rats. Int J Pharm Pharm Sci 2017;9(3):111-115. 